\title{
Channelling Norwegian hydropower towards greener currents: The challenge of conflicting environmental concerns?
}

\author{
Audun Ruud ${ }^{1}$, Helene Egeland ${ }^{1}$, Gerd B. Jacobsen ${ }^{1}$, Jørgen K. Knudsen ${ }^{1, *}$, William M. \\ Lafferty $^{1}$ \\ ${ }^{1}$ SINTEF Energy Research, Norway \\ *Corresponding author. Tel: +47 22965971, Fax: +47 22965980,E-mail: audun.ruud@sintef.no
}

\begin{abstract}
Nearly 100 percent of electricity used in Norway stems from hydropower, but no further large-scale production is politically viable. There is however increased interest in hydropower as both a supplement to the national energy supply and as provider of balance within the European energy system. Interest focuses on: (1) increased pumping and storage; (2) upgrading of existing hydropower installations; and (3) small-scale hydro production. Such measures are also considered as climate-change mitigation. As a fourth developmental path there are also alternative processes aiming at reinforcing environmental concerns in existing hydropower, not least by revising granted licenses. These processes coincide with a reinforced focus on biodiversity. This dual environmental challenge is also enhanced by Norway's follow-up of the EU Directive on renewable energy (RES) and the EU Water Framework Directive (WFD). In this context, we here assess current political and regulatory practice in Norway, focusing on the status of environmental concerns, and the challenges Norwegian hydropower policy faces by the implementation of the EU Directives. The policy challenge is manifest as 'tradeoffs' among hydropower priorities at both the strategic and project-specific levels; and is further enhanced by lack of clarity as to the ultimate impact of the relevant EU Directives.
\end{abstract}

Keywords: EU, Renewable Energy Directive, Water Framework Directive, Norwegian hydropower, policy, governance, Environmental Policy Integration (EPI), trade-off

\section{Introduction}

Nearly $100 \%$ of electricity consumption in Norway stems from hydropower. Since 2001 it has been politically stated that the 'era of new large-scale hydropower constructions is over' [1]. At the same time, there is an increased interest for hydropower as a way of meeting national climate change commitments and to sustain the national power balance. Furthermore, there is an increased interest for extending the export potential of hydropower 'balance' to Europe, given the increased intermittent renewable (wind) power production in the EU. In parallel, there is growing concern over the environmental status of Norwegian water courses. Norway is committed by the former and current EU Directives on renewable electricity and energy (RES) (adopted in 2001 and 2008, respectively), as well as the EU Water Framework Directive (WFD; adopted in 2000) [2] [3]. ${ }^{1}$ The directives clearly involve 'trade-offs' among competing concerns for security of energy supply; climate change; biodiversity; and improved water quality.

In this light, there are in principle three major options for further development of hydropower in Norway: (1) extend the potential for pumping and storage to increase capacity for balancing; (2) refurbish and/or upgrade existing power production; and (3) promote smallscale hydropower. The third option can also be related to the first, since upgrading can entail increased storage capacity. Furthermore, with respect to environmental concerns for the water courses, there is a fourth 'path' which implies a stronger regard for environmental concerns in

\footnotetext{
${ }^{1}$ While not assuming the full responsibilities of EU membership Norway participates fully in the EU internal market, as well as being involved in related EU policy areas. This is since 1994 regulated through the Agreement on the European Economic Area (EEA).
} 
the formal processes for revising licenses for existing facilities - with possible modifications and reductions in the production volume.

Referring to these four developmental paths, the present paper begins by assessing current political and regulatory practice for hydropower in Norway, focusing on the status of environmental concerns, and the emerging challenge of trade-offs between climate-change and biodiversity. The paper then goes on to discuss the challenges met by the implementation of the EU WFD and RES Directives. The empirical data are based on an ongoing research project on the political and regulatory framework for hydropower, and the related follow-up at the project level. This includes insights from four recent case studies [4] [5] [6]. ${ }^{2}$

As a conceptual approach to the analysis, we employ the notion of Environmental Policy Integration (EPI), which is an increasingly valuable tool for dealing with the potential synergies and trade-offs related to the goal of sustainable development. As indicated, any further development of hydropower in Norway involves competing economic, social and environmental concerns. Article 11 of the 'Principles' of the treaty of the European Union states that: 'Environmental protection requirements must be integrated into the definition and implementation of the Union's policies and activities, in particular with a view to promoting sustainable development'[7]. Our analysis is guided by the meaning of this stricture within the context of the academic discourse on EPI [8].

In the following section, we present the analytical and methodological approach. Section 3 presents the main features of the current Norwegian political and regulatory framework, as well as the challenges raised by the EU RES and WFD Directives. In section 4 we discuss how these challenges have been met - and can be assumed to be met in near future, given the established national framework. And in section 5 we provide our conclusions.

\section{Analytical framework}

The challenge of integrating environmental concerns into economic and social policies is a key focus of the EPI approach. De-coupling economic drivers from environmental degradation is particularly crucial to achieve 'sustainable development' [9]. According to a principal interpretation of EPI, environmental concerns should be accorded 'principled priority' in order to reduce the degradation of the life-sustaining capacities of affected ecosystems [8] [9]. In the present context, EPI provides a basis for analysing trade-offs between environmental and other concerns relevant for hydropower, from policy strategies down to specific projects. Several mechanisms for applying EPI principles have been explored and analysed in Europe during the last twenty years [10] [11].

Applying EPI principles to the further development of hydropower in Norway, we begin by identifying the trade-off processes- and arenas where different actors pursue different interests and concerns. A trade-off process in this context is understood as the decisionmaking procedures in place for resolving conflicts of interest in specific hydropower arenas at both the strategic and project-specific levels.

\footnotetext{
${ }^{2}$ The research project Governance for Renewable Electricity Production (GOVREP; 2009-12) focuses on policies and regulations for renewable electricity in Norway and Sweden. The project is part of the Norwegian Centre for Environmental Design of Renewable Energy (CEDREN), and is co-funded by the Norwegian Research Council, Statkraft and Agder Energy Production.
} 
Such conflicts generally arise when hydro power production is assessed vis-à-vis measures to improve the environment, particularly since strong environmental measures often imply changes in the discharge of water, often affecting established energy production. The challenge of integrating environmental concerns also depends on the perspective employed. Are the concerns addressed at the European, national or local level of analysis? The underlying assumption here is that a European perspective will imply a stronger priority of climate-change mitigation over more local environmental concerns, including biodiversity. However, biodiversity is also a global challenge and entails international commitments.

It is in this light that we aim to identify and assess factors that condition the prioritization and application of environmental concerns. Context-specific studies of this kind are also decisive in order to supplement the traditional techno-economic approach of understanding the phasein of new energy production [12].

\section{The political-regulatory framework for integrating environmental concerns in Norwegian hydropower production}

Given its dominant role, hydropower is a crucial part of the general energy policy strategy in Norway. The public management of water courses began as early as 1887 with legislation which is still valid, though frequently revised and amended. The first Protection Plan for Watercourses was adopted in 1973, followed by three additional plans plus a supplement (1980, 1986, 1993 and 2005). In 1981 the Parliament adopted a Master Plan for Water Resources which ranks watercourses according to economic and environmental dimensions as well as the degree of expected political controversy. The Plan has since become the central reference for hydropower development.

Licenses for hydropower production are granted on the basis of both a general Energy Act (covering all forms of energy production and distribution) and more specific legislation on water regulations and water resources (two legal acts)[6]. In addition, there are several laws pertaining to the protection of water course environment directly relevant for hydropower. ${ }^{3}$ Although these laws do not imply unalterable environmental requirements, they do provide important factors that must be considered in relation to licensing, and changes in licenses.

The four developmental paths for hydropower in Norway (as stipulated above), must, therefore, be based on the general strategic framework put forth in the Master Plan and protection plans, as well as more specific legislative requirements. With respect to pumping and storage, however, a more substantial exploitation of this potential in a European perspective is still not accounted for in any existing plan. The existing legislative framework applies, though questions can be raised as to whether this is sufficient given new challenges as to the need for stronger coordination between different licenses within the same watercourse system, most particularly with regard to affected environmental concerns.

The refurbishment and upgrading $(\mathrm{R} / \mathrm{U})$ of existing installations has been encouraged by political signals, being perceived as environmentally sound as it contributes to increased hydropower with lower environmental impacts than traditional hydropower production since

\footnotetext{
${ }^{3}$ Although the environmental focus in the water legislation traditionally is related to the local environmental context, there is an increasing focus on biodiversity following from international commitments. In particular, a Biodiversity Law was adopted in 2009, and there is also a specific protection regime for the salmon: The Law on Salmons and freshwater fish, together with regulations for protected salmon rivers and fjords. This also constitutes the Norwegian follow-up of international commitments for the preservation of salmons.
} 
new physical interventions are not required. No overall target for R/U (or for any other aspect of hydropower generation for that matter) has been set at the national level. Licenses for R/U are granted within the legislative framework referred to above.

Small-scale hydropower (up to 10 MW installed capacity) has also been increasingly encouraged by both national and regional authorities, not least as a way of providing new economic activity and income for rural areas. Although guidelines for the planning and impact assessment of small-scale hydro projects at the county level were adopted in 2006, there is no overall national plan. Licenses for small-scale hydro projects are granted directly from the NVE, without additional approval from the MoPE. Another important development in the regulatory framework is a parliamentary decision from 2005 which allows the construction of small-scale projects below $1 \mathrm{MW}$ to be constructed within protected water courses.

Efforts to improve the environmental standard of existing hydropower projects in regulated water courses constitute an important means for improving the water course environment in Norway. ${ }^{4}$ Processes where trade-offs are being practiced include: (1) The revision of licenses - where the main objective is to rectify earlier regulatory initiatives which mainly emphasized the provision of electricity as a welfare benefit with little concern for environmental impacts. (2) The revision of regulations affecting water discharge. This includes licenses containing specific conditions and requirements, such as the protection of salmon. In such cases the particular condition stipulated has more leverage than other concerns, but is still weighted in relation to the consequences of restricting the hydropower production. (3) Finally, with direct relevance for newer licenses (after 1973), it is also possible to reinforce environmental measures applying more general standards, as long as the net energy output is not reduced.

In all of these processes the Norwegian licensing authority (the NVE), is authorized to coordinate related assessments and trade-off processes. The actual importance of the affected concerns will, however, vary from case to case as a consequence of the character of the process itself, as well as the case-specific context. Important aspects of these processes also involve actors at the regional and local levels. The management of hydropower is, however, characterised by sectoral fragmentation, as reflected by the different laws and plans mentioned above. The NVE, together with the Ministry of Petroleum and Energy (MoPE), manage and administer the laws concerning hydropower resources and the related licensing procedures. The Protection Plans, the Master Plan and the laws concerning nature protection and land use planning are, on the other hand, managed by the Ministry of the Environment (MoE) and the Directorate for Nature Conservation (DN).

Furthermore, in a number of cases related to hydropower development, particularly largescale hydropower plants, the NVE provides only recommendations, whereas the MoPE makes the final decision, which in some cases must also be approved by the Parliament. In the course of these processes, divergences between the 'MoPE'- and 'MoE-segments' often materialise, based on their different mandates.

\footnotetext{
${ }^{4}$ The four case studies conducted as part of the GOVREP project, focus on different processes of changing the conditions in already granted licenses; the opportunities for integration of environmental concerns, and the tradeoffs being made at different levels of governance[4] [5]: (1) Iveland: Upgrading of an existing hydropower plant; (2) Laudal: Revision of regulation of water currents concerning a special condition requiring protection of the salmon stock; (3) Suldalslågen: Revision of regulation of water currents in order to balance the hydro power production and the protection of the salmon stock in a more optimal manner, and (4) Aura: General revision of conditions in a granted license.
} 


\subsection{Follow-up of the EU Directives}

It is within this general 'policy landscape' that new international commitments - on both climate-change and biodiversity - must be adapted and reconciled. The EU Directive on the promotion of renewable energy (RES), adopted in 2008, sets national, binding targets covering electricity, heating/cooling as well as biofuels, and is part of the EU's climate policy strategy [2]. The EU RES Directive is, however, still not (as of December 2010) formally adopted by Norway. Due to the extent of Norway's renewable energy resources (both hydropower and wind power), one expects that the EU will require an ambitious national target for Norway (through the EEA Agreement) [13]. Related to this process, Norway is currently negotiating with Sweden in order to establish a common scheme for tradable certificates for renewable electricity, and a protocol stipulating the principles of the system was signed by the two countries in December 2010. These efforts build on similar, but failed, negotiations in 2006 [14].

A major objective of the EU Water Framework Directive (WFD) is to identify water courses where constructions or operations have affected the ecological status [2]. In such cases, one speaks of 'highly modified water courses'; for which the objective is to achieve 'good ecological potential' (as distinguished from a 'good ecological status' for 'purer' water courses) [2]. In principle, all water courses affected by larger hydropower activities are considered to be highly modified. The WFD was adopted in 2000, but the inclusion in the EEA Agreement was delayed and Norway did not start implementation before 2006. By focusing on 29 pilot areas Norwegian authorities aimed at coordinating their initial follow-up with the common EU implementation. The EU WFD Directive has stimulated a debate on the future usage of water resources, and the implementation of the Directive has evoked conflicts of interest between energy production and nature conservation in Norway.

The 'complete' Norwegian follow-up is to be coordinated with the second phase of the EU implementation plan, that is 2010-15. This will provide a more complete picture of the effect of the WFD in Norway. The River Basin Management Plans and Programmes of measures (as stipulated by the Directive) related to the first phase were approved by the Government in June 2010 [15]. An important part of the Norwegian follow-up is the general principle that concrete measures must be based on sectoral legislation. In general, this means that the NVE continues to coordinate the license processes for hydropower as before, only now being 'informed' of the regional water management plans. The environmental goals of the plans are, therefore, only to be considered along with other existing laws regulating water courses.

\section{What is the role of environmental concerns?}

As indicated in section 3, Norway's hydropower policy has traditionally been based on a strategic framework which can be characterised as a 'trade-off arena' at the national level. In recent years, the Master Plan's ranking of potential projects based on specific criteria can also be associated with Norway's ambitions on sustainable development (SD). The issue of tradeoffs among the three dimensions of SD - economic, social and environmental - is thus increasingly difficult to resolve at both the political-strategic level and in relation to individual projects. Given a general lack of specificity in the Master Plan for hydropower, however, the actual assessments of trade-offs are primarily taking place at the local-regional project level. This has been confirmed by the four case studies of the GOVREP project [4] [5].

Another important finding from these case studies is that environmental concerns must be viewed as compatible with economic interests if they are to be accommodated at all [4] [5]. In 
particular, in relation to revision of regulation of water discharges (Suldalslågen, Laudal) economic interests related to the salmon stock (fishing, tourism) entailed protection measures, including restrictions of the hydropower power production [4] [5]. At the same time, in other cases, the focus on economic interests has led to the priority of increased hydropower production, whereas biodiversity-related environmental concerns have been offered only limited attention [4] [5]. Hence, although environmental concerns constitute the point of departure for many revisions of existing licenses and installations, pro-environment tradeoff's are not stipulated in advance.

Economic concerns also seem to be decisive for small-scale hydropower: The main driver here is clearly a general concern for sustained economic development in rural areas [6]. Small-scale hydropower is, however, mentioned as a relevant factor in Norway's most recent climate-change policy strategy [16]. Small-scale hydro is also promoted as environmentally benign because no reservoirs are needed, in contrast to large-scale hydro projects. Small-scale initiatives do not, therefore, represent an option for an increased RES balancing of the European energy market. Further, small-scale installations have a number of potentially negative impacts on water course environments, not least due to the high and increasing number of installations. Again, we see no evidence in our studies of overall trade-offs among these partly contradictory objectives [6].

The potential effects and impacts of increased pumping and storage in relation to European energy production has not yet been assessed, nor included in the climate-change policy strategy. Norwegian politicians increasingly refer to this option, however, as a climate-policy measure. Pumping and storage is also seen as an alternative way of fulfilling Norway's impending target under the EU RES Directive. Thus far, however, no public figures have been supplied as to the potential of these and other 'new RES' sources for Norway's obligations under the EU Directive.

$\mathrm{R} / \mathrm{U}$ initiatives have, however, been framed as a climate-change mitigation option, although not specifically in relation to the overall national climate-change policy strategy. In an R/U project studied within GOVREP (Iveland) the 'climate-argument' was employed to justify the upgrading of the installation [4]. This reflects a perception of $\mathrm{R} / \mathrm{U}$ cases as contributing to an overall reduction of greenhouse gas emissions by hydropower supply. Once again, however, no overall target for $\mathrm{R} / \mathrm{U}$ has yet been stipulated.

The most relevant SD trade-off processes are thus conducted at a project level within the framework of an outdated Master Plan. More recent national policy targets for climate change, biodiversity and improved water management have thus far not been substantially affected by the national-strategic trade-off decisions. This is most clearly illustrated by the implementation of the WFD Directive. The follow-up here has thus far not resulted in - or been directed by - any overall national objectives, although the process has contributed to a strengthened focus on environmental concerns in water course management and development. In the years to come, the WFD will, nevertheless, require a broader environmental input to the assessment of hydropower projects. As shown in the GOVREP case studies, however, the eventual effect of this input will probably vary from case to case, and from process to process [4] [5].

Finally we can mention that, by examining the regional management plans conducted during the first phase of the WFD follow-up, one is struck by the comprehensive mapping and assessment of the different factors leading to highly modified water courses [6]. At the same 
time, however, no clear provisions as to the further development of hydropower - with eventual direct impact on specific projects - are stipulated by the plans. The main approach is to delegate the responsibility for the formulation of mitigating measures to the energy-sector authorities. Together with the Government's decision to treat environmental concerns primarily in relation to the licensing of hydropower projects - and to only 'be informed' as to the implications of the regional water management plans - the situation clearly reinforces an impression of a relatively passive and incremental Norwegian follow-up of the WFD.

\section{Conclusion: The overall status of environmental concerns}

The traditional project-specific approach to trade-offs in relation to Norwegian hydropower development reflects a generally 'robust' approach. The environmental dimension is, however, of more recent and increasing importance as a crucial factor in hydropower licensing and development. In addition, both climate-change mitigation and biodiversity are increasingly important national concerns; but, at the same time, concerns that increasingly will conflict with each other. Whereas climate-change will figure more prominently at the strategic level, biodiversity concerns will generally be activated more strongly at the local level and related to specific projects. No overall assessment or specific guidelines exist at to the management of these complex 'trade-off' challenges. The challenge is manifest in growing confrontations between protagonists for stronger environmental concerns and protagonists of more hydropower; and is being directly incorporated into the different mandates of environmental and energy authorities. A stronger focus on biodiversity, and new efforts of establishing a more sector-encompassing water management through the implementation of the WFD, has not altered the relative positions of the responsible agencies thus far. The setting of a new EU-related national RES target, has the potential to induce changes which can reinforce the need to develop hydropower, and thereby lead to even stronger conflicts with biodiversity. The final act in the shaping of Norway's water management system, as well as the future of Norwegian hydropower in an EU energy context, is thus strongly dependent on the follow-up of both the RES and WFD Directives. Whether at the level of national energy-climate strategy, or specific regional-local waterpower projects, the issue of 'trade-offs' is the name of the Norwegian sustainable-development game.

\section{References}

[1] White Paper 37, 2000-01, On hydropower and the power balance (in Norwegian), Oslo: Ministry of Petroleum and Energy (MoPE).

[2] OJEC, Directive 2000/60/EC of the European Parliament and of the Council of 23 October 2000 establishing a framework for Community action in the field of water policy. In Official Journal of the European Communities (OJEC), 22 Dec. 2000, L 327/1.

[3] OJEU, Directive 2009/28/EC of the European Parliament and of the Council of 23 April 2009 on the promotion of the use of energy from renewable sources and amending and subsequently repealing Directives 2001/77/EC and 2003/30/EC. In Official Journal of the European Union, 5 June 2009, L 140/16.

[4] H. Egeland \& G.B. Jacobsen, On the case studies of Laudal and Iveland (in Norwegian), Technical Report, Trondheim: SINTEF Energy Research, 2011a, forthcoming.

[5] H. Egeland, H. \& G.B. Jacobsen, On the case studies of Suldalslågen and Aura (in Norwegian), Technical Report, Trondheim: SINTEF Energy Research, 2011b, forthcoming. 
[6] J.K. Knudsen, Norwegian hydropower management and the integration of environmental concerns, Technical Report, Trondheim: SINTEF Energy Research, 2011, forthcoming.

[7] CEC, Consolidated Version on the Treaty of the Functioning of the European Union, in Official Journal of the European Union, C 115/47, 9 May 2009. Brussels: The European Communities.

[8] J.K. Knudsen, Environmental Policy Integration: Conceptual clarification and comparative analysis of standards and mechanisms, Dissertation submitted to obtain the degree of Doctor. Enschede: University of Twente, 2009.

[9] W.M. Lafferty \& E. Hovden, Environmental Policy Integration: Towards an Analytical Framework, Environmental Politics, Volume 12, Issue 3, 2003, pp. 1 - 22.

[10] A.J. Jordan \& A. Lenschow (eds), Innovation in Environmental Policy? Integrating the Environment for Sustainability, Cheltenham UK: Edward Elgar, 2008.

[11] W.M. Lafferty (ed.), Governance for Sustainable Development, Cheltenham UK: Edward Elgar, 2004.

[12] W.M. Lafferty \& A. Ruud A. (eds), Promoting Sustainable Electricity in Europe: Challenging the Path Dependency of Dominant Energy Systems, Cheltenham UK: Edward Elgar, 2008.

[13] A. Ruud \& J.K. Knudsen, Renewable energy policy making in the EU: What has been the role of Norwegian stakeholders?, Teknisk Rapport TR A6860, Trondheim: SINTEF Energy Research AS, 2009.

[14] J. Knudsen, A. Ruud \& O.M. Larsen, Norway: Promoting new renewables in a hydrobased petroleum economy', in W.M. Lafferty and A. Ruud (eds): Promoting Sustainable Electricity in Europe: Challenging the Path Dependency of Dominant Energy Systems. Cheltenham UK: Edward Elgar, 2008, pp. 250-278.

[15] Ministry of the Environment, Royal decree approving regional management plans according to the WFD Directive (in Norwegian), Oslo: Ministry of the Environment, 2009.

[16] Committee Recommendations 145, Innstilling fra energi- og miljøkomiteen om norsk klimapolitikk (in Norwegian). Oslo: Parliament, 2008. 